\title{
Integração ao Ensino Superior em um curso de Pedagogia
}

\author{
Mariana Coralina do Carmo \\ Soely Aparecida Jorge Polydoro
}

\section{Resumo}

Este trabalho teve como objetivo analisar e comparar a integração ao Ensino Superior de universitários de um curso de Pedagogia e verificar se houve variação de acordo com a situação acadêmica, faixa etária e situação de trabalho. A coleta de dados foi coletiva e incluiu o preenchimento do Questionário de Vivências Acadêmicas (QVA) por 68 estudantes matriculados na primeira ou última série do curso. Quanto à situação acadêmica, foram encontradas diferenças significativas em 15 subescalas, sendo sempre favorável aos concluintes. A faixa etária dos ingressantes diferenciou significativamente sua integração em três subescalas. A percepção pessoal de competência foi significativamente diferente ao se considerar a situação de trabalho dos ingressantes. A faixa etária dos ingressantes diferenciou significativamente sua integração em duas subescalas. As análises expostas confirmam que a integração ao Ensino Superior é um fenômeno multifacetado e inserido em uma rede de inter-relações que envolvem as características dos estudantes.

Palavras chaves: Estudantes universitários, ensino superior, integração.

\section{Integrating Higher Education in a course of Education}

\begin{abstract}
This study aimed to analyze and compare the integration of higher education from a university pedagogy course and see if there was variation according to academic standing, age and employment status. Data collection was collective and included the completion of the Academic Experiences Questionnaire (QVA) for 68 students enrolled in first or last series of the course. With regard to academic standing, significant differences were found in 15 subscales and always favorable to the graduates. The age of entering students differ significantly in their integration into three subscales. The personal perception of competence was significantly different when considering the work situation of freshmen. The age of entering students differ significantly in their integration into two subscales. The analysis confirms that the integration exposed to higher education is a multifaceted phenomenon and inserted into a web of interrelationships that involve the characteristics of students.
\end{abstract}

Keywords: College students, higher education, integration.

\section{Integración a la enseñanza superior en una facultad de pedagogía}

\section{Resumen}

El objetivo de este trabajo fue analizar y comparar la integración a la enseñanza superior de universitarios de una facultad de Pedagogía y verificar si hubo variación de acuerdo con la situación académica, período etario y situación de trabajo. La recopilación de datos fue colectiva e incluyó responder al Cuestionario de Vivencias Académicas (CVA) por 68 estudiantes matriculados en el primer o último año de la facultad. En relación a la situación académica, se encontraron diferencias significativas en 15 sub-escalas, siendo siempre favorable a los concluyentes. El período etario de los ingresantes diferenció significativamente su integración en tres subescalas. La percepción personal de habilidad fue significativamente diferente al considerarse la situación de trabajo de los ingresantes. El período etario de los ingresantes diferenció significativamente su integración en dos subescalas. Los análisis expuestos confirman que la integración a la enseñanza superior es un fenómeno multifacético e insertado en una red de inter-relaciones de las que participan las características de los estudiantes.

Palabras claves: Estudiantes universitarios, educación superior, integración. 


\section{Introdução}

Nos últimos anos, pudemos observar o crescimento quantitativo do sistema de Ensino Superior no Brasil, o que tem gerado um corpo discente com características cada vez mais diversificadas (Colossi, Consentino, \& Queiroz, 2001). Tal fato coloca, para as instituições, além do conhecido problema do acesso, o desafio de responder às necessidades dessa nova população (Nico, 2000). Essa heterogeneidade pode ser identificada na maior representatividade de estudantes oriundos das diferentes classes sociais, localidades geográficas e grupos étnicos; crescente diferenciação por gênero; maior presença de acadêmicos mais velhos, trabaIhadores e envolvidos na gestão de papéis familiares, entre outros aspectos. Além disso, também está associada ao percurso escolar prévio, ao nível de dificuldade de ingresso, às experiências, necessidades, expectativas e metas e à persistência e grau de enfrentamento de dificuldades e desafios. Tal fenômeno tem sido observado não só no Brasil, mas também em países da América e da Europa (Nowell \& Hedges, 1998; Almeida, Soares, \& Ferreira, 1999).

Para que a universidade possa cumprir sua função, promovendo o desenvolvimento integral dos estudantes, é essencial a ampliação do conhecimento sobre si mesma e sobre seus acadêmicos (Cuervo \& Corellan, 1998; Sbardelini e cols., 1999). Conhecer profundamente os processos que se estabelecem no Ensino Superior é contribuir para a resposta da instituição aos novos desafios a que é submetida, como as mudanças socioculturais e políticas educacionais, novos sistemas de avaliação e financiamento, desenvolvimento científico e tecnológico, outros espaços e tempos educativos, além da própria heterogeneidade da população que a procura.

A compreensão sobre como os estudantes vivenciam o ambiente universitário e tomam suas decisões quanto à vida acadêmica não significa apenas fazer um levantamento acerca de informações sobre as características dos estudantes ou do ambiente institucional, mas precisa incluir o estudo do processo de interação desses dois elementos e as mudanças produzidas por essa experiência em ambos. A integração à universidade é constituída no cotidiano destas relações. Trata-se de um processo multifacetado construído na troca entre as expectativas, percepções e características dos estudantes, e a estrutura, normas, componentes organizacionais e comunidade que compõem a universidade. Dessa interação, são observadas mudanças de natureza pessoal, interacional e institucional (Almeida e cols., 1999; Pascarella \& Terenzini, 2005; Polydoro e cols., 2001; Teixeira, Dias, Wottrich, \& Oliveira, 2008).

$\mathrm{O}$ conceito de mudança refere-se às alterações de caráter qualitativo ou quantitativo que ocorrem nas características cognitivas e afetivas dos estudantes ao longo do tempo, não implicando em direção e não contendo juízo de valor. Vários estudos têm se dedicado ao entendimento das mudanças dos estudantes no Ensino Superior e seus resultados. Ao sistematizar investigações dessa natureza, Pascarella e Terenzini (2005) agruparam as teorias e modelos obtidos em dois grandes grupos teóricos: teorias desenvolvimentistas e modelos de impacto. O primeiro trata da natureza, estrutura, dimensões e processos de crescimento dos universitários. De modo geral, as teorias desenvolvimentistas descrevem as dimensões e as fases do desenvolvimento intraindividual. A mudança é entendida como decorrente da maturação psicológica ou biológica, de experiências individuais e da interação entre indivíduo e meio (Ferreira, 1991; Pascarella \& Terenzini, 2005). É evidente a importância da assunção de que o desenvolvimento ocorre ao longo do período que o estudante passa na universidade. Os conhecimentos já produzidos sobre esse processo e os estudos dele decorrentes são subsídios que podem e devem ser utilizados pelas instituições na construção do projeto pedagógico, de políticas institucionais e de programas específicos.

O foco de análise dos modelos de impacto está principalmente na origem ambiental ou sociológica da mudança do estudante e menos na sua natureza e resultado. Isto é, buscam explicar as mudanças que ocorrem nos estudantes a partir de variáveis externas ao indivíduo, considerando a rede de reciprocidade entre os aspectos pessoais, institucionais e ambientais que compõem os processos formadores (Ferreira, 1991; Mercuri \& Polydoro, 2003; Pascarella \& Terenzini, 2005). Os modelos de impacto apresentam, como características gerais, a ênfase no papel e importância do contexto no qual o estudante age e pensa como fontes potenciais de influência sobre as suas mudanças cognitivas e não cognitivas (Pascarella \& Terenzini, 2005; Almeida \& Ferreira, 1999). O contexto universitário, em particular, tem sido concebido como um ambiente que pode oferecer oportunidades mais substanciais para mudanças em relação a outras instituições sociais (Astin, 1996). Essa condição deve-se à diversidade de experiências que desafiam valores, atitudes e convicções, à maior abertura e à oportunidade de praticar novos papéis e relações (Almeida, e cols.; Faria \& Santos, 1998; Gonçalves \& Cruz, 1988; Pascarella \& Terenzini, 2005;). Apesar das tendências apresentadas, a formação superior é vivida de forma singular por cada um dos discentes.

A universidade emerge, assim, como um contexto propiciador dos diferentes processos de transição acadêmica, social e afetiva por que passa o estudante nesse período, em especial quanto à transição do Ensino Médio para o Ensino Superior e do Ensino Superior para o mundo socioprofissional. O ingresso no Ensino Superior tem sido considerado uma das transições mais importantes ao longo da trajetória acadêmica do indivíduo. As experiências iniciais do primeiro ano do curso são tidas como determinantes para os níveis de sucesso e satisfação acadêmica, e dos padrões de desenvolvimento ao longo da graduação (Almeida, e cols., 2002; Batista \& Almeida, 2002; Pascarella \& Terenzini, 2005). As pesquisas sobre a vida universitária evidenciam, em termos gerais, que o estudante, durante seu processo de formação, vivencia diferentes situações, algumas concluídas com sucesso, recompensando o empenho e os esforços, e outras associadas às decepções, frustrações e insa- 
tisfações, que dificultam, em diferentes níveis, a trajetória do estudante. Como, por exemplo, a falta de compromisso com o curso ou a carreira, o baixo desempenho acadêmico, acarretando a reprovação, ou mesmo a falta de condição de continuidade do curso, levando à evasão (Mercuri, Ajub, \& Bariani, 1998).

Os altos índices de evasão e de reprovação no Ensino Superior denotam que a universidade não tem sido bem-sucedida na resposta a essa situação. Os estudantes, freqeentemente, se veem privados de suportes adequados capazes de facilitar a transformação dos múltiplos desafios a que são submetidos em situações de desenvolvimento pessoal (Abreu, Leitão, Paixão, Brêda, \& Miguel, 1996). Nesse percurso, para se buscar soluções mais comprometidas com a realidade integral dos universitários, é imprescindível a compreensão de suas características e de como vivenciam sua formação, evidenciando a necessidade do desenvolvimento de estudos de avaliação sobre o universitário e a sua relação com a instituição.

\section{Objetivos}

Direcionado pela necessidade de se conhecer a percepção de estudantes sobre as características das suas vivências na universidade, o presente trabalho teve, como objetivo geral, descrever, analisar e comparar a integração ao Ensino Superior de estudantes ingressantes e concluintes de um curso de Pedagogia. Como objetivo específico, pretendeu-se verificar se há variação de integração ao Ensino Superior de ingressantes e concluintes, quanto à faixa etária e situação de trabalho dos estudantes.

\section{Método}

Tendo em vista os objetivos anteriormente apontados, desenvolveu-se uma pesquisa no ano de 2007 do tipo descritiva, referente à integração de estudantes de um curso noturno de formação de professores de uma universidade pública do estado de São Paulo. Com o intuito de desenvolver esta pesquisa de acordo com os critérios éticos preconizados pela Resolução 196/96 do Conselho Nacional de Saúde, esta pesquisa foi submetida à apreciação pelo Comitê de Ética em Pesquisa da universidade em questão (CAAG - 01850.146.000-08) e os participantes foram orientados sobre a natureza da pesquisa, os objetivos e as condições de estudo. Foram utilizados, para a coleta de dados com a finalidade de atingir os objetivos desta pesquisa, além do Termo de Consentimento Livre e Esclarecido, o Questionário de Vivências Acadêmicas (QVA), construído por Leandro S. Almeida (Universidade do Minho, Portugal) e Joaquim A. G. Ferreira (Universidade de Coimbra, Portugal) em 1997, dentro de um projeto do Centro de Estudos em Educação e Psicologia da Universidade do Minho. Esse instrumento volta-se para a avaliação das condições de integração do estudante ao contexto universitário, focalizando as dimen- sões pessoais, interpessoais, acadêmicas e institucionais desse processo. Está organizado em 170 itens de formato likert de cinco pontos, distribuídos em 17 subescalas $^{1}$.

A resposta a cada item deve ser dada na escolha de cinco opções, a saber:

1 - Nada a ver comigo, totalmente em desacordo, nunca acontece; 2 - Pouco a ver comigo, muito em desacordo, poucas vezes acontece; 3 - Algumas vezes de acordo comigo, e outras não, algumas vezes acontece, e outras não; 4 - Bastante a ver comigo, muito de acordo, acontece muitas vezes; 5 - Tudo a ver comigo, totalmente de acordo, acontece sempre.

Trata-se de um instrumento de screening ou despiste, essencialmente centrado nas vivências adaptativas dos alunos, que procura abranger um vasto leque de dimensões, excluindo uma avaliação aprofundada e circunscrita a aspectos particulares, caracterizando-se como um instrumento de autorrelato direcionado para a avaliação extensiva das diferentes dimensões do processo, não se propondo a uma avaliação circunscrita e aprofundada de aspectos particulares (Almeida e cols., 1999). Importa ressaltar que alguns itens do QVA possuem redação no sentido inverso ${ }^{2}$. Nesse caso, é necessário inverter a pontuação indicativa nesses itens antes da análise das respostas, de forma que o resultado seja interpretado sempre na mesma direção, isto é, que uma pontuação superior esteja associada a uma percepção positiva da integração ao Ensino Superior. No que concerne à realidade brasileira, ocorreu a tradução do QVA por Villar e Santos (2001) a fim de torná-lo compatível com os aspectos socioculturais (costume, comportamento, sistema educacional, expressões idiomáticas), modificando $75 \%$ dos itens. Nesse estudo, houve a adaptação e tradução do QVA, atendo-se mais particularmente à ortografia, gramática e expressões idiomáticas. No que diz respeito à verificação da consistência interna do instrumento, em um estudo, 357 alunos ingressantes da área de Humanas de uma universidade particular de São Paulo responderam ao QVA com o objetivo de verificação da consistência interna, por meio do cálculo do coeficiente alfa de Cronbach em cada uma das 17 subescalas, comparando-se os coeficientes obtidos a partir da amostra de universitários brasileiros e da amostra de portugueses. Assim, comparando-se os índices de consistência interna encontrados na pesquisa realizada em Portugal com os índices obtidos no estudo, as variações ocorridas não foram significativas, sugerindo a presença de consistência interna, o que viabiliza sua aplicação no contexto universitário brasileiro (Santos, 1999). Cabe salientar que se atentou para

1 São: adaptação ao curso, adaptação à instituição, envolvimento em atividades extracurriculares, gestão de tempo, métodos de estudo, gestão de recursos econômicos, ansiedade na avaliação, relacionamento com colegas, relacionamento com familiares, relacionamento com professores, bases de conhecimento autonomia, desenvolvimento de carreira, bem-estar físico, bemestar psicológico, autoconfiança e percepção de competências.

2 São as questões: 4, 6, 8, 9, 10, 11, 12, 14, 15, 17, 18, 19, 21, 23 $25,27,28,29,32,37,39,43,45,47,50,53,66,67,69,72,73,76$, $77,78,80,83,85,86,87,91,92,98,99,100,103,104,106,115$ $119,121,122,123,125,127,128,129,131,132,136,142,144$ $147,151,154,157,161,166$ e 167. 
a exploração dos dados de maneira quantitativa, buscando atender aos objetivos da pesquisa, deixando, portanto, de estabelecer de maneira mais aprofundada a discussão dos dados, o que poderia ser feito através de entrevistas ou até mesmos de questões abertas.

\section{Participantes}

Participaram desse estudo 68 estudantes do curso de Pedagogia de uma instituição pública de Ensino Superior do Estado de São Paulo. No que diz respeito ao sexo, dentre os ingressantes, eram 29 alunos do sexo feminino, representando $87,9 \%$, e quatro alunos do sexo masculino $(12,1 \%)$. Quanto aos concluintes, $100 \%$ eram do sexo feminino. Para os alunos ingressantes, a idade mínima observada foi de 17 anos e a máxima, de 47 anos, com média de 22,2 anos. No que diz respeito aos concluintes, a idade mínima foi de 20 anos e máxima de 31 anos, com média de 23,9 anos. Quanto à atividade remunerada, dentre os ingressantes, temos que seis $(18,2 \%)$ não trabalhavam, 17 (51,5\%) trabaIhavam, mas não na área do curso que estavam cursando e $10(30,3 \%)$ trabalhavam na área do curso. Já entre os concluintes, três deles (8,6\%) não exerciam atividade remunerada, nove $(25,7 \%)$ exerciam atividade remunerada, mas não na área da graduação e $23(65,7 \%)$ exerciam atividade remunerada na área da graduação. Em relação à coleta de dados, dada a autorização do coordenador de curso, deuse o contato prévio com os professores responsáveis pelas disciplinas para agendamento do dia e horário da aplicação do instrumento. Os participantes foram localizados em suas salas de aula, em disciplina típica do semestre, e receberam informações quanto aos objetivos da pesquisa, procedimento a ser adotado, uso a ser dado às informações obtidas, garantia quanto ao sigilo e à autonomia para decidir participar ou não do estudo. As respostas ao questionário ocorreram de forma individual, mas no coletivo da sala de aula. A duração aproximada da aplicação foi de 60 minutos. No início da aplicação, foi retomada a explicação sobre os objetivos da pesquisa, sua justificativa e uso dos dados obtidos. O pesquisador acompanhou os estudantes na leitura do Termo de Consentimento Livre e Esclarecido, ficando à disposição para informações necessárias.

\section{Resultados e Discussão}

Diante dos objetivos propostos para este estudo, procurou-se identificar e analisar a integração na Educação Superior de estudantes do curso de Pedagogia de uma instituição pública de Ensino Superior, assim como analisar sua relação com variáveis de caracterização do estudante. A análise dos dados obtidos foi realizada através de procedimentos estatísticos específicos. De maneira geral, foram utilizadas provas estatísticas de caráter descritivo e inferencial com a utilização do software SPSS 13.0. A seguir, segue a Tabela 1 referente à estatística descritiva da integração ao Ensino Superior.

Ao considerar as respostas obtidas por meio do QVA nacional, pode-se verificar que a média foi, para o ingressante, 3,04 e, para o concluinte, 3,61; o desvio padrão foi, respectivamente, 0,16 e 0,34. Esse dado indica que os estudantes perceberam-se próximos ao ponto médio, demonstrando integração moderada ao Ensino Superior. A fim de ampliar essa análise, foi calculado, para cada grupo, o intervalo médio a partir da adição e da subtração do desvio padrão à média obtida para a obtenção dos valores máximos e mínimos, respectivamente. $O$ intervalo médio de integração para os ingressantes foi de 2,88 a 3,20 e, para os concluintes, de 3,27 a 3,95.

A menor média verificada para os alunos ingressantes foi na dimensão bem-estar físico $(m=2,03)$ e desvio padrão de 0,44 , enquanto que, para os concluintes, foi a dimensão envolvimento em atividades extracurriculares, com média de $2,46(\mathrm{dp}=0,37)$. No que diz respeito à maior média, observamos que os ingressantes, na dimensão adaptação à instituição, obtiveram média de $3,63(d p=0,37)$ e os alunos concluintes, média de 4,12 na dimensão relacionamento com a família, com desvio padrão de 0,92.

Apesar de não se pretender, neste momento, a comparação de ingressantes e concluintes, é possível identificar que o limite inferior do intervalo médio dos concluintes foi superior ao ponto máximo do intervalo médio dos ingressantes, o que denota uma integração ao Ensino Superior mais satisfatória entre os concluintes. Esta tendência também é observada quando se analisam as maiores e menores médias nas dimensões. Ressalta-se não caber, aos objetivos dessa pesquisa, a comparação entre ingressantes e concluintes, mas fica aberta a possibilidade de comparação uma vez que os dados convergem para isto.

Os ingressantes apresentam médias inferiores ao intervalo médio do grupo em seis das 17 dimensões: bem-estar físico $(m=2,03)$, envolvimento em atividades extracurriculares $(m=2,44)$, relacionamento com professores $(m=2,56)$, bem-estar psicológico $(m=2,61)$, realização de exames $(m=2,75)$ e gestão de recursos econômicos $(m=2,76)$. Para os concluintes, duas dimensões pontuaram abaixo do intervalo médio do grupo: envolvimento em atividades extracurriculares $(m=2,46)$ e relacionamento com professores $(m=2,84)$. Nota-se que ambas as dimensões também tiveram pontuação inferior entre os ingressantes.

Quanto aos valores apresentados acima do intervalo médio, foram observadas cinco dimensões no grupo dos ingressantes, em ordem crescente: métodos de estudo $(m=3,33)$, desenvolvimento de carreira $(m=3,59)$, adaptação à instituição $(m=3,63)$, relacionamento com a família $(m=3,79)$ e gestão de tempo $(m=3,67)$. E, no grupo de concluintes, três dimensões obtiveram médias superiores, sendo: relacionamento com colegas $(m=3,97)$, gestão de tempo $(\mathrm{m}=3,97)$ e relacionamento com a família $(\mathrm{m}=4,12)$.

Para continuidade das análises, foi aplicado o teste de normalidade Kolmogorov-Smirnov para definição dos testes estatísticos a serem utilizados na comparação entre os 
Tabela 1. Estatística descritiva da integração ao Ensino Superior

\begin{tabular}{|c|c|c|c|c|c|c|}
\hline & Situação Acadêmica & $\mathbf{N}$ & Mínimo & Máximo & Média & $\begin{array}{l}\text { Desvio } \\
\text { Padrão }\end{array}$ \\
\hline \multirow{2}{*}{ Gestão de recursos econômicos } & ingressante & 33 & 1 & 4 & 2,76 & 0,72 \\
\hline & concluinte & 35 & 1 & 4 & 3,28 & 0,85 \\
\hline \multirow{2}{*}{ Relacionamento com colegas } & ingressante & 31 & 2 & 3 & 3,17 & 0,32 \\
\hline & concluinte & 34 & 2 & 4 & 3,97 & 0,50 \\
\hline \multirow{2}{*}{ Métodos de estudo } & ingressante & 33 & 2 & 3 & 3,33 & 0,36 \\
\hline & concluinte & 32 & 2 & 4 & 3,57 & 0,41 \\
\hline \multirow{2}{*}{ Adaptação à instituição } & ingressante & 33 & 2 & 4 & 3,63 & 0,37 \\
\hline & concluinte & 34 & 2 & 4 & 3,82 & 0,38 \\
\hline \multirow{2}{*}{ Adaptação ao curso } & ingressante & 33 & 2 & 3 & 3,20 & 0,32 \\
\hline & concluinte & 35 & 2 & 4 & 3,56 & 0,55 \\
\hline \multirow{2}{*}{ Relacionamento com professores } & ingressante & 31 & 1 & 3 & 2,56 & 0,30 \\
\hline & concluinte & 33 & 1 & 3 & 2,84 & 0,48 \\
\hline \multirow{2}{*}{$\begin{array}{l}\text { Envolvimento em atividades } \\
\text { extracurriculares }\end{array}$} & ingressante & 33 & 1 & 3 & 2,44 & 0,34 \\
\hline & concluinte & 34 & 1 & 3 & 2,46 & 0,37 \\
\hline \multirow{2}{*}{ Desenvolvimento de carreira } & ingressante & 33 & 2 & 4 & 3,59 & 0,46 \\
\hline & concluinte & 34 & 2 & 4 & 3,76 & 0,59 \\
\hline \multirow{2}{*}{ Autonomia pessoal } & ingressante & 33 & 2 & 3 & 3,07 & 0,30 \\
\hline & concluinte & 31 & 2 & 4 & 3,65 & 0,43 \\
\hline \multirow{2}{*}{ Percepção pessoal de competências } & ingressante & 32 & 2 & 3 & 3,05 & 0,28 \\
\hline & concluinte & 34 & 2 & 4 & 3,64 & 0,46 \\
\hline \multirow{2}{*}{ Bases de conhecimento para o curso } & ingressante & 33 & 2 & 3 & 2,97 & 0,39 \\
\hline & concluinte & 35 & 2 & 4 & 3,85 & 0,60 \\
\hline \multirow{2}{*}{ Autoconfiança } & ingressante & 32 & 2 & 3 & 2,89 & 0,26 \\
\hline & concluinte & 33 & 3 & 4 & 3,92 & 0,42 \\
\hline \multirow{2}{*}{$\begin{array}{l}\text { Realização de exames (ansiedade na } \\
\text { avaliação) }\end{array}$} & ingressante & 32 & 2 & 3 & 2,75 & 0,36 \\
\hline & concluinte & 34 & 2 & 4 & 3,65 & 0,47 \\
\hline \multirow{2}{*}{ Relacionamento com a família } & ingressante & 33 & 2 & 4 & 3,79 & 0,55 \\
\hline & concluinte & 35 & 1 & 5 & 4,12 & 0,92 \\
\hline \multirow{2}{*}{ Bem-estar psicológico } & ingressante & 32 & 1 & 4 & 2,61 & 0,66 \\
\hline & concluinte & 32 & 2 & 4 & 3,33 & 0,53 \\
\hline \multirow{2}{*}{ Bem-estar físico } & ingressante & 33 & 1 & 2 & 2,03 & 0,44 \\
\hline & concluinte & 33 & 2 & 4 & 3,51 & 0,53 \\
\hline \multirow{2}{*}{ Gestão de tempo } & ingressante & 32 & 2 & 4 & 3,67 & 0,48 \\
\hline & concluinte & 34 & 2 & 5 & 3,97 & 0,80 \\
\hline \multirow{2}{*}{ Total } & ingressante & 30 & 2 & 3 & 3,04 & 0,16 \\
\hline & concluinte & 28 & 2 & 4 & 3,61 & 0,34 \\
\hline \multirow[t]{2}{*}{ Válidos } & ingressante & 30 & & & & \\
\hline & concluinte & 28 & & & & \\
\hline
\end{tabular}


Tabela 2. Diferenças encontradas na integração ao Ensino Superior entre ingressantes e concluintes.

\begin{tabular}{|c|c|c|c|c|c|}
\hline Dimensões & Situação Acadêmica & $\mathrm{N}$ & $\begin{array}{l}\text { Ponto } \\
\text { Médio }\end{array}$ & $U$ & Sig. \\
\hline \multirow{3}{*}{ Gestão de recursos econômicos } & Ingressante & 33 & 27,85 & & \\
\hline & Concluinte & 35 & 40,77 & & \\
\hline & Total & 68 & & 358 & $0,00^{*}$ \\
\hline \multirow{3}{*}{ Relacionamento com colegas } & Ingressante & 31 & 19,35 & & \\
\hline & Concluinte & 34 & 45,44 & & \\
\hline & Total & 65 & & 104 & $0,00^{*}$ \\
\hline \multirow{3}{*}{ Métodos de estudo } & Ingressante & 33 & 27,98 & & \\
\hline & Concluinte & 32 & 38,17 & & \\
\hline & Total & 65 & & 362,50 & $0,02^{*}$ \\
\hline \multirow{3}{*}{ Adaptação à instituição } & Ingressante & 33 & 29,09 & & \\
\hline & Concluinte & 34 & 38,76 & & \\
\hline & Total & 67 & & 399 & $0,04^{*}$ \\
\hline \multirow{3}{*}{ Adaptação ao curso } & Ingressante & 33 & 26,14 & & \\
\hline & Concluinte & 35 & 42,39 & & \\
\hline & Total & 68 & & 301,50 & $0,00^{*}$ \\
\hline \multirow{3}{*}{ Relacionamento com professores } & Ingressante & 31 & 26,63 & & \\
\hline & Concluinte & 33 & 38,02 & & \\
\hline & Total & 64 & & 329,50 & $0,01^{*}$ \\
\hline \multirow{3}{*}{ Autonomia pessoal } & Ingressante & 33 & 21,08 & & \\
\hline & Concluinte & 31 & 44,66 & & \\
\hline & Total & 64 & & 134,50 & $0,00^{*}$ \\
\hline \multirow{3}{*}{ Percepção pessoal de competências } & Ingressante & 32 & 21,30 & & \\
\hline & Concluinte & 34 & 44,99 & & \\
\hline & Total & 66 & & 153,50 & $0,00^{*}$ \\
\hline \multirow{3}{*}{ Bases de conhecimento para o curso } & Ingressante & 33 & 21,08 & & \\
\hline & Concluinte & 35 & 47,16 & & \\
\hline & Total & 68 & & 134,50 & $0,00^{*}$ \\
\hline \multirow{3}{*}{ Autoconfiança } & Ingressante & 32 & 17,19 & & \\
\hline & Concluinte & 33 & 48,33 & & \\
\hline & Total & 65 & & 22 & $0,00^{*}$ \\
\hline \multirow{3}{*}{ Realização de exames (ansiedade na avaliação) } & Ingressante & 32 & 18,94 & & \\
\hline & Concluinte & 34 & 47,21 & & \\
\hline & Total & 66 & & 78 & $0,00^{*}$ \\
\hline \multirow{3}{*}{ Relacionamento com a família } & Ingressante & 33 & 27,36 & & \\
\hline & Concluinte & 35 & 41,23 & & \\
\hline & Total & 68 & & 342 & $0,00^{*}$ \\
\hline \multirow{3}{*}{ Bem-estar psicológico } & Ingressante & 32 & 22,72 & & \\
\hline & Concluinte & 32 & 42,28 & & \\
\hline & Total & 64 & & 199 & $0,00^{*}$ \\
\hline \multirow{3}{*}{ Bem-estar físico } & Ingressante & 33 & 17,50 & & \\
\hline & Concluinte & 33 & 49,50 & & \\
\hline & Total & 66 & & 16,50 & $0,00^{*}$ \\
\hline \multirow[t]{3}{*}{ Total } & Ingressante & 30 & 17,13 & & \\
\hline & Concluinte & 28 & 42,75 & & \\
\hline & Total & 58 & & 49 & $0,00^{*}$ \\
\hline
\end{tabular}


Tabela 3. Diferenças na integração ao Ensino Superior quanto à situação de trabalho

\begin{tabular}{|l|l|l|l|l|l|}
\hline \multirow{2}{*}{ Dimensão } & Exercício de atividade remunerada & Situação Acadêmica & N & Ponto Médio & Sig. \\
\hline \multirow{2}{*}{$\begin{array}{l}\text { Percepção } \\
\text { pessoal de } \\
\text { competências }\end{array}$} & Não exerce & Exerce, mas não na área da graduação & Ingressante & 6 & 17,33 \\
\cline { 2 - 6 } & Exerce, na área da graduação & Ingressante & 16 & 12,66 & \\
\cline { 2 - 6 } & Total & Ingressante & 10 & 22,15 & \\
\cline { 2 - 6 } & & & 32 & & $0,04^{*}$ \\
\hline
\end{tabular}

grupos de variáveis. Apesar da identificação de distribuição normal no total e em dezesseis das dezessete dimensões analisadas, como a dimensão autoconfiança não apresentou dados normais, optou-se por utilizar os testes não paramétricos para toda a análise de dados desta pesquisa, coerentemente com as recomendações estatísticas (Levin, 1987). Para comparações entre duas variáveis, foi utilizado o teste Mann-Whitney (teste U) e, para comparações entre mais variáveis, foi utilizado o teste Kruskal-Wallis. $\mathrm{Na}$ Tabela 2, são apresentados os dados correspondentes à comparação da integração ao Ensino Superior por situação acadêmica.

Foi possível notar que os dois grupos se diferenciaram na percepção de integração ao Ensino Superior e em quase todas as suas dimensões. Só não foram encontradas diferenças significativas nas subescalas: envolvimento em atividades extracurriculares, desenvolvimento de carreira e gestão de tempo. Apresentaram diferenças significativas todas as outras subescalas e, nestas, os alunos concluintes sempre apresentaram ponto médio superior quando comparados aos ingressantes. Já era esperado que os veteranos, no caso dessa pesquisa, os alunos concluintes, pelo tempo de vida e consequente experiência na universidade e no curso, perceberiam de forma mais satisfatória sua integração. Para Astin e Kent (1983), a vivência acadêmica dos estudantes traz benefícios importantes ao desenvolvimento pessoal e à adaptação ao meio acadêmico. O desenvolvimento maior dos concluintes em função da vivência já assinalada e que os diferencia dos ingressantes evidencia-se nas questões assinaladas por Gomes Ferreira e Neto (2000), especialmente naquelas relacionadas à competência, autonomia, integridade, identidade, administração das emoções e relações interpessoais.

Por outro lado, ingressantes e concluintes vivenciavam de forma similar as demandas recorrentes do planejamento do tempo e cumprimento de prazos e do desenvolvimento de carreira, assim como as dificuldades do envolvimento em atividades extracurriculares. Como observado por Oliveira (2003), quanto à dimensão acadêmica, a fase final de curso assemelha-se aos desafios de ingresso, pois o excesso de atividades e exigências acadêmicas faz desta fase um período complicado. Em relação à situação de trabalho, os estudantes foram organizados da seguinte maneira: não exercem atividade remunerada, exercem atividade remunerada, mas não na área da graduação, e exercem atividade remunerada na área de graduação. Pode-se observar que apenas a dimensão percepção pessoal de competências de ingressantes apresentou diferença significativa, sendo favorável àqueles que trabalhavam na área. $\mathrm{Na}$ Tabela 3 , temos as diferenças na integração ao Ensino Superior quanto à situação de trabalho.

Para todas as outras subescalas, não houve diferença significativa na integração ao Ensino Superior conforme a situação de trabalho na integração de ingressantes e concluintes.

Oliveira (2003), ao caracterizar as percepções de estudantes concluintes sobre aspectos de suas vivências relacionadas ao seu desenvolvimento profissional/vocacional, pessoal, acadêmico e social, também observou que, dentre as mudanças que caracterizavam o momento de saída da universidade, o concluinte relatava o reconhecimento de suas competências na área de formação. Na Tabela 4 estão apresentados os dados de comparação dos estudantes por faixa etária.

Em relação à faixa etária, foram encontradas diferenças significativas para os ingressantes nas dimensões relacionamento com professores e percepção pessoal de competências, e, para os concluintes, nas subescalas gestão de recursos econômicos e relacionamento com a família. Nas subescalas que foram estatisticamente diferentes para os ingressantes, os alunos de 22 a 25 anos apresentaram pontos médios superiores às outras faixas etárias. Para os concluintes, os pontos médios significativamente superiores foram obtidos por alunos com até 21 anos. No caso da subescala relacionamento com a família, Almeida, Soares e Ferreira (1999) salientam que as médias mais elevadas traduzem-se em níveis também mais elevados de interdependência entre o estudante e sua família. E, de fato, a pontuação dos ingressantes foi maior no caso dos dados obtidos nesta pesquisa.

Em síntese, foi observada uma integração moderada, próxima à média prevista no instrumento, com diferenças entre ingressantes e concluintes e destes conforme a faixa etária e a situação de trabalho. A média global para os ingressantes foi de 3,04, com desvio padrão de 0,16 e, para 
Tabela 4. Diferenças na integração ao Ensino Superior e em suas dimensões quanto à faixa etária.

\begin{tabular}{|c|c|c|c|c|c|}
\hline Dimensões & Faixa etária & Situação Acadêmica & $\mathbf{N}$ & Ponto Médio & Sig. \\
\hline \multirow{8}{*}{ Gestão de recursos econômicos } & \multirow[b]{2}{*}{ até 21 anos } & Ingressante & 23 & 16,30 & \\
\hline & & Concluinte & 7 & 28,36 & \\
\hline & \multirow[b]{2}{*}{ de 22 a 25 anos } & Ingressante & 4 & 22,88 & \\
\hline & & Concluinte & 19 & 15,00 & \\
\hline & \multirow[b]{2}{*}{26 anos em diante } & Ingressante & 6 & 15,75 & \\
\hline & & Concluinte & 9 & 16,28 & \\
\hline & \multirow[b]{2}{*}{ Total } & Ingressante & 33 & & 0,42 \\
\hline & & Concluinte & 35 & & $0,01^{*}$ \\
\hline \multirow{8}{*}{$\begin{array}{l}\text { Relacionamento com } \\
\text { professores }\end{array}$} & \multirow[b]{2}{*}{ até 21 anos } & Ingressante & 21 & 13,79 & \\
\hline & & Concluinte & 7 & 16,86 & \\
\hline & \multirow[b]{2}{*}{ de 22 a 25 anos } & Ingressante & 4 & 27,38 & \\
\hline & & Concluinte & 18 & 15,72 & \\
\hline & \multirow[b]{2}{*}{26 anos em diante } & Ingressante & 6 & 16,17 & \\
\hline & & Concluinte & 8 & 20,00 & \\
\hline & & Ingressante & 31 & & $0,02^{*}$ \\
\hline & Total & Concluinte & 33 & & 0,58 \\
\hline \multirow{8}{*}{$\begin{array}{l}\text { Percepção pessoal de } \\
\text { competências }\end{array}$} & \multirow[b]{2}{*}{ até 21 anos } & Ingressante & 22 & 14,50 & \\
\hline & & Concluinte & 6 & 19,67 & \\
\hline & \multirow[b]{2}{*}{ de 22 a 25 anos } & Ingressante & 4 & 28,00 & \\
\hline & & Concluinte & 19 & 14,55 & \\
\hline & \multirow[b]{2}{*}{26 anos em diante } & Ingressante & 6 & 16,17 & \\
\hline & & Concluinte & 9 & 22,28 & \\
\hline & & Ingressante & 32 & & $0,02^{*}$ \\
\hline & Total & Concluinte & 34 & & 0,13 \\
\hline \multirow{8}{*}{ Relacionamento com a família } & \multirow[b]{2}{*}{ até 21 anos } & Ingressante & 23 & 17,93 & \\
\hline & & Concluinte & 7 & 27,43 & \\
\hline & \multirow[b]{2}{*}{ de 22 a 25 anos } & Ingressante & 4 & 18,25 & \\
\hline & & Concluinte & 19 & 15,50 & \\
\hline & \multirow[b]{2}{*}{26 anos em diante } & Ingressante & 6 & 12,58 & \\
\hline & & Concluinte & 9 & 15,94 & \\
\hline & \multirow[b]{2}{*}{ Total } & Ingressante & 33 & & 0,46 \\
\hline & & Concluinte & 35 & & $0,02^{*}$ \\
\hline
\end{tabular}


os concluintes, média de 3,61 e desvio padrão de 0,34. As dimensões com valores superiores ao intervalo médio para os ingressantes foram: métodos de estudo, desenvolvimento de carreira, adaptação à instituição, relacionamento com a família e gestão de tempo. E, para os concluintes, relacionamento com colegas, gestão de tempo e relacionamento com a família. No que diz respeito aos valores inferiores ao intervalo médio, para os ingressantes: bem-estar físico, envolvimento em atividades extracurriculares, relacionamento com professores, bem-estar psicológico, realização de exames e gestão de recursos econômicos. E, para os concluintes: envolvimento em atividades extracurriculares e relacionamento com professores.

Foram obtidas diferenças significativas entre a integração ao Ensino Superior de ingressantes e concluintes em todas as dimensões estudadas, exceto envolvimento em atividades curriculares e desenvolvimento de carreira, sendo sempre favoráveis aos concluintes. Os ingressantes diferenciaram-se quanto à situação de trabalho na dimensão percepção pessoal de competência, sendo superior aos que exercem atividade remunerada associada à área da graduação e quanto à idade nas dimensões relacionamento com os professores e percepção pessoal de competência, com maiores valores aos estudantes de 22 a 25 anos. A integração dos concluintes só se diferenciou conforme a idade e nas dimensões gestão de recursos econômicos e relacionamento com a família, favorável aos estudantes com até 21 anos.

As análises expostas confirmam que a integração ao Ensino Superior é um fenômeno multifacetado e inserido em uma rede de inter-relações, que envolve as características dos estudantes e as experiências de formação que vivenciam. Além disso, é sabido que se dá de forma contínua e que é dinâmica, ou seja, sofre mudanças como processo definido pelas relações pessoais e institucionais. Como já apontado por outros autores, a integração constrói-se com uma troca entre as características, expectativas e habilidades dos estudantes e o contexto social e acadêmico da instituição (Almeida \& Ferreira, 1999). Ao atentarmos para as questões relacionadas à qualidade de permanência desses estudantes, podemos destacar o estudo de Silva Filho e cols. (2007), que nos diz os motivos de evasão de estudantes em nosso Ensino Superior.

O estudo das vivências acadêmicas dos estudantes ingressantes e concluintes do curso noturno de Pedagogia, considerando as variáveis estudadas, possibilitou não apenas identificar suas características, como também analisálas de maneira a melhor compreender a gama de relações que se faz presente no processo de integração do estudante ao Ensino Superior.

Vale ressaltar que este estudo, realizado com estudantes de um único curso de uma instituição pública de Ensino Superior, não reflete a realidade das condições de integração da população total dos estudantes do referido curso e turno, nem dos estudantes de outros cursos que estão inseridos no contexto da Educação Superior brasileira.
A apreciação acerca do papel do Ensino Superior sobre a formação do estudante há muito tem destacado a importância do desenvolvimento da pessoa de forma integral, o que ultrapassa o compromisso com a preparação profissional. Em decorrência, avolumam-se as pesquisas acerca do impacto das experiências de formação superior no desenvolvimento dos estudantes (Teixeira e cols., 2008; Silva Filho e cols., 2007; Pascarela \& Terenzini, 2005). Considerando a expansão e diversidade do sistema de Ensino Superior brasileiro e de seus estudantes, estudos voltados para o conhecimento dos processos envolvidos neste nível de formação são relevantes, já que o conhecimento sobre as experiências de formação, suas características e relações contribui para o estabelecimento de políticas e práticas institucionais intencionalmente dirigidas ao desenvolvimento integral do estudante.

Percebe-se que a maioria dos estudantes que chega ao Ensino Superior, mesmo que não possua expectativas muito positivas em relação ao curso que vai frequentar e/ou se sinta inseguro relativamente aos novos contatos sociais, papéis e rotinas que tem de desempenhar, possui expectativas positivas em relação ao seu novo estilo de vida e é quase sempre com certo orgulho, partilhado com a família e os amigos, que o estudante se inicia nesta nova caminhada da sua vida pessoal, social e acadêmica.

A importância da integração ao contexto universitário pode ser observada nos resultados de investigações como a de Ajub (1998), cujo levantamento de dificuldades dos estudantes aponta predominantemente para problemas relacionados a essa integração. Outro ponto é a alta porcentagem de alunos que evadem das universidades, deixando seus cursos ao se defrontarem com dificuldades decorrentes da vida universitária, tais como problemas financeiros, problemas de saúde na família ou com a própria saúde, casamento, gravidez, distância para chegar à Instituição de Ensino Superior, desencanto com o curso, problemas relacionados ao trabalho, serviço militar, transferência para outra IES, entre outras.

Dessa forma, a literatura nos mostra que os estudantes universitários, de forma geral, apresentam dificuldades e problemas nas suas vivências acadêmicas, principalmente no período pós-ingresso, ou seja, no primeiro ano na universidade. Estes problemas estão relacionados às condições de integração acadêmica e social e influenciam na decisão do estudante universitário de permanecer ou evadir (Teixeira e cols., 2008).

A partir dos resultados do presente estudo, foi identificada a condição de integração dos estudantes do curso de Pedagogia noturno considerada moderada, o que reflete que, se por um lado, algumas dimensões apresentam valores satisfatórios, por outro, indica que os estudantes apresentam dificuldades que devem ser objeto de intervenção.

Este estudo compreendeu que as maiores dificuldades dos estudantes ingressantes do curso de Pedagogia noturno estavam relacionadas aos aspectos de bem-estar físico, bem-estar psicológico, envolvimento em atividades extracurriculares, relacionamento com professores, gestão 
de recursos econômicos e ansiedade na avaliação. E, para os concluintes, o envolvimento em atividades extracurriculares e o relacionamento com professores.

Dessa forma, os resultados alcançados destacam a importância da promoção de condições institucionais para a integração do estudante ao Ensino Superior e indicam que sejam reunidos esforços para a orientação dos estudantes do curso noturno, no que diz respeito às dimensões pessoal, interpessoal, acadêmica, institucional e de carreira.

Além disso, este estudo sugere a realização de novas pesquisas que tenham como participantes estudantes de instituições públicas como também privadas de Ensino Superior, considerando a expansão do sistema e suas implicações para a compreensão dessa população. Além disso, são necessários estudos que descrevam as condições de integração de estudantes de diferentes turnos e cursos, com o objetivo de identificar os aspectos específicos desse processo.

Assim sendo, entende-se que as instituições de Ensino Superior têm um papel ativo neste processo, proporcionando vivências acadêmicas capazes de coadjuvar o sucesso global do estudante desde o primeiro momento, pois educar, no sentido de promover o desenvolvimento, passa por proporcionar vivências positivas.

\section{Referências}

Abreu, M. V., Leitão, L. M., Paixão, M. P., Brêda, M. S. J., \& Miguel, J. P. (1996). Aspirações e projetos pessoais, condições de vida e de estudo dos alunos do Ensino Superior de Coimbra. Psychologica 16, 33-61.

Almeida, L. S., \& Ferreira, J. A. (1999). Adaptação e rendimento acadêmico no Ensino Superior: fundamentação e validação de uma escala de avaliação de vivências acadêmicas. Psicologia: Teoria, Investigação e Prática, 1, 157-170.

Almeida, L. S., Soares, A. P., \& Ferreira, J. A. G. (1999). Adaptação, rendimento e desenvolvimento dos estudantes no Ensino Superior: construção/validação do Questionário de Vivências Acadêmicas. Série - Relatórios de Investigação. Centro de Estudos em Educação e Psicologia. Universidade do Minho.

Almeida, L. S., Soares, A. P. e Ferreira, J. A. G. (2002). Questionário de Vivências Acadêmicas (QVA-r): Avaliação do ajustamento dos estudantes universitários. Avaliação Psicológica, 2, 81-93.

Ajub, J. C. (1998). O ingresso na universidade: as dificuldades encontradas e suas formas de superação. Relatório de Iniciação Científica. Unicamp - Campinas.

Astin, A. W. (1996). O estudo do impacto causado pela Universidade. Tradução para o Curso de Especialização em Avaliação à Distância, Universidade de Brasília, 4, 109-134. Original em: F. K. Satage, A. Guadalupe, J. P. Bean, D. Hossler, G. Kuh. College students: The evolving nature of research. ASHE Reader Series: Simon \& Shuster Custom.

Astin, A. W., \& Kent, L. (1983). Gerder roles in transition: Research and policy implications for higher education. Journal of higher education, 54, $309-324$.

Batista, R. G. R., \& Almeida, L. S. (2002). Desafios da Transição e Vivência Acadêmicas: Análise segundo a Opção de Curso e Mobilidade. Em A. S. Pouzada, L. S. Almeida \& R. M. Vasconcelos (Eds.), Contextos e dinâmicas da vida académica (pp. 167-174). Guimaraes: Universidade do Minho.

Colossi, N., Consentino, A., \& Queiroz, E. G. (2001). Mudanças no contexto do Ensino Superior no Brasil: uma tendência ao ensino colaborativo. Revista FAE, 4(1), 49-58.

Cuervo, J. C. P., \& Corellan, A. V. (1998). Evaluación de las necesidades de los alumnos universitarios sobre el servicio de orientación de la Universidad de la Coruña (SAPE). Congresso Galaico-português de psicopedagogi. Actas do IV Congresso Galaico-Português de Psicopedagogia (pp. 398-403), Braga.

Faria, L., \& Santos, N. L. (1998). Validação de uma escala de concepções pessoais de competência no contexto universitário. Congresso Galaico-português de psicopedagogi. Actas do IV Congresso Galaico-Português de Psicopedagogia (pp. 144-150), Braga.

Ferreira, J. A. (1991). As teorias interaccionistas e o desenvolvimento do estudante do Ensino Superior. Revista Portuguesa de Pedagogia, XXV, 91-105.

Gomes Ferreira, J. A., \& Neto, M. L. (2000). Inventário de relações interpessoais (IRI): procedimentos de construção e validação. Em A. P. Soares e cols. (Eds.), Transição para o Ensino Superior. Braga: Universidade do Minho.

Gonçalves, O., \& Cruz, J. F. (1988). A organização e implementação de serviços universitários de consulta psicológica e desenvolvimento humano. Revista Portuguesa de Educação, 1(1), 127-145.

Mercuri, E., \& Polydoro, S. A. J. (2008). O compromisso com o curso no processo de permanência/evasão no Ensino Superior: algumas contribuições. Em E. Mercuri \& S. Polydoro (Orgs), Estudante universitário: características e experiências de formação. Taubaté, SP: Cabral Editora e Livraria Universitária.

Mercuri, E. N. G. Da S., Ajub, J. C., \& Bariani, I. C. D. (1998). Dificuldades encontradas por universitários ingressantes. Anais do IV Congresso de Psicologia Escolar (p. 141), João Pessoa, Paraíba.

Nico, J. B. (2000). O Conforto Acadêmico do(a) Caloiro(a Em A. P. Soares e cols. (Eds.), Transição para o Ensino Superior. Braga: Universidade do Minho. 
Nowell, A., \& Hedges, L. V. (1998). Trends in gender differences in academic achievement from 1960 a 1994. Sex Roles, 39, 21-43.

Oliveira, J. (2003). Finalização do curso de graduação - que momento é esse?. Trabalho de Conclusão de Curso. Faculdade de Educação, Universidade de Campinas, Campinas, São Paulo.

Pascarella, E. T., \& Terenzini, P. T. (2005). How college affects students: a third decade of research (2a ed.). San Francisco: Jossey-Bass.

Polydoro, S. A. J, Primi, R., Serpa, M. de N. da F., Zaroni, M. M. H., Pombal, K. C. P. (2001). Desenvolvimento de uma Escala de Integração ao Ensino Superior. Psico-USF, 6(1), 11-17.

Santos, A. P. dos. (1999). Diagnóstico do fluxo de estudantes nos cursos de graduação da UFOP. Retenção, diplomação e evasão. Avaliação, 4(14), 55-66.
Sbardelini, E. T. B. e cols. (1999). Situação Acadêmica do Aluno da USF: Reopção, Reprovação e Evasão. Anais do /l Congresso de Pesquisa e Extensão. Bragança Paulista, São Paulo.

Silva Filho, R. L. L. e cols. (2007). A evasão no Ensino Superior Brasileiro. Cadernos de Pesquisa, 37, 132.

Teixeira, M. A. P., Dias, A. C. G., Wotrich, S. H. E, \& Oliveira, A. M. Adaptação à Universidade em jovens calouros. Psicologia Escolar E Educacional, 12(1).

Villar, J. D. e Santos, A.A.A. (2001). Questionário de Vivência Universitária: adaptação para estudantes brasileiros. Manuscrito não-publicado, Universidade São Francisco, Itatiba, São Paulo.

\section{Sobre as Autoras}

Mariana Coralina do Carmo (mari.coralina@gmail.com)

Universidade Estadual de Campinas, Campinas - SP

Soely Aparecida Jorge Polydoro (polydoro@unicamp.br)

Universidade Estadual de Campinas, Campinas - SP

\section{Correspondência}

Mariana Coralina do Carmo

Rua Macedo Soares, 850

Cidade Universitária II, Campinas - SP

CEP 13083-130 